\title{
Ocorrência de patulina em uva fina (Vitis vinifera L. cv. “Rubi”) com sinais de podridão ácida
}

\author{
Occurrence of patulin in grape (Vitis vinifera L. Cv. 'Rubi') with indication \\ of the sour rout
}

\author{
Glória Maria Menezes Caldas ${ }^{\mathrm{I}}$ Renata Cabrera de Oliveira ${ }^{\mathrm{II}}$ \\ Dauri José Tessmann ${ }^{\mathrm{III}}$ Miguel Machinski Junior ${ }^{\mathrm{IV}}$
}

\section{RESUMO}

A podridão ácida é uma patologia das videiras, de alta freqüência nos períodos quentes e chuvosos, em conseqüencia do desenvolvimento de fungos e bactérias em seus frutos. Um dos gêneros de fungos responsáveis por esta doença é o Penicillium spp., que poderá levar à produção de micotoxinas, como a patulina. Neste trabalho, foi realizada uma investigação sobre a podridão ácida e a ocorrência de patulina em uvas Itália (Vitis vinifera $\mathbf{L}$. cv. Rubi) cultivadas no município de Marialva, Brasil. Foram avaliados os seguintes tratamentos: (I) testemunha sem sintomas de podridão ácida; (II) amostras com sintomas, sem a remoção das bagas infectadas; (III) amostras com sintomas, com a remoção das bagas infectadas, (IV) amostras com sintomas da doença, com a remoção das bagas infectadas e desinfecção com hipoclorito. A cromatografia em camada delgada foi utilizada para a determinação de patulina. Nas amostras analisadas, não foi detectada contaminação por esta micotoxina.

Palavras-chave: patulina, videira, fitopatologia, micotoxinas.

\section{ABSTRACT}

Sour rout is a pathology of bunch grapes occurring in hot and rainy periods. Several fungi and bacteria are associated with this disease, including Penicilium spp. In the present study it was carried out an investigation to determine the incidence of sour rout and patulin in grapes (Vitis vinifera L. cv. Rubi) cultivated in Marialva, Brazil. The treatments studied were the following: (I) samples without symptoms of sour rout, (II) samples with symptoms and without cleaning stage, (III) samples with symptoms and with cleaning stage and (IV) samples with symptoms, cleaning stage and washing with hypochlorite. The thin-layer chromatography was utilized to determine the presence and quantification of patulin. Patulin was not detected in any samples.

Key words: patulin, bunch grape, phytopathology, mycotoxins.

\section{INTRODUÇÃO}

A uva foi introduzida no Brasil pelos colonizadores portugueses no ano de 1532, no Estado de São Paulo. Os cultivares de Vitis vinifera procedentes de Portugal e da Espanha expandiram-se para outras regiões do país. Na década de 70 , verificouse um aumento da área de parreirais com cultivares $\boldsymbol{V}$. vinifera, oriundas de empresas multinacionais que se instalaram na região da Serra Gaúcha. Neste mesmo período, surgiu a viticultura voltada para a produção de uva fina de mesa na região noroeste do Estado do Paraná, caracterizada por pequenas propriedades com uso de mão-de-obra familiar (PROTAS et al., 2004). Segundo o IBGE (2006), o Brasil produziu 1.291.382 toneladas de uva em 2004. O Estado do Paraná foi responsável por 7,5\% da produção nacional, sendo que a sua maior produção foi de uva fina para mesa $(89,95 \%)$, seguida da uva para a produção de vinho $(10,05 \%)$.

As doenças fúngicas constituem-se num dos principais problemas para a viticultura, como a antracnose, a escoriose, o míldio, o oídio, a podridão cinzenta, a podridão da uva madura, a podridão amarga, a podridão ácida, a fusariose, a roseliniose, entre outras (SONEGO \& GARRIDO, 2004). Na região noroeste do Estado do Paraná, um grande problema é a podridão ácida, devido à temperatura e à umidade elevadas no período da primeira colheita, ou seja, nos meses de novembro a janeiro (GENTA et al., 2001).

A podridão ácida é causada por um complexo de microrganismos que inclui fungos dos gêneros:

\footnotetext{
IPrograma de Pós-graduação em Ciências da Saúde, Universidade Estadual de Maringá (UEM), Maringá, PR, Brasil.

"Curso de Farmácia, UEM, Maringá, PR, Brasil.

IIIDepartamento de Agronomia, UEM, Maringá, PR, Brasil.

IV Departamento de Análises Clinicas, UEM, Maringá, PR, Brasil. E-mail: mmjunior@uem.br. Autor para correspondência.
} 
Aspergillus, Penicillium, Cladosporium, Alternaria, Diplodia e Rhizopus, bem como leveduras e bactérias acéticas, como Gluconobacter spp. e Acetobacter spp. (GIOVANNINI, 1999; LOUREIRO \& MALFEITOFERREIRA, 2003). Esta patologia foi relatada pela primeira vez na Itália por BISIACH et al. (1986) e, freqüentemente, inicia no pedicelo ou, por dano, na película das bagas. A podridão ácida é facilmente reconhecida pela coloração marrom-clara, decomposição da polpa, pelas películas escurecidas e aderidas ao pedúnculo e pelo odor de acetato de etila ou ácido acético (BISIACH et al., 1986; GUERZONI \& MARCHETTI, 1987; SONEGO \& GARRIDO, 2004). A podridão ácida reduz o preço e a competitividade das uvas do grupo Itália no mercado nacional. Por isso, o produtor realiza uma etapa de limpeza, com o corte das bagas que apresentam sinais desta patologia para melhorar aparentemente a qualidade da uva.

As micotoxinas, produtos do metabolismo normal de alguns fungos que proliferam em alimentos e ração animal, acarretam, quase sempre, graves danos à saúde do homem e dos animais. O interesse científico sobre as mesmas ocorreu em 1960, na Inglaterra, com a morte de aves com hepatite aguda necrosante após a ingestão de ração contaminada com aflatoxinas. As principais micotoxinas detectadas na uva, como a patulina, a citrinina e a ocratoxina A, põem em risco a saúde dos consumidores, bem como reduzem a qualidade da uva e de seus derivados, como o vinho.

A patulina é um metabólito secundário produzido por diversas espécies de fungos dos gêneros Penicillium, Aspergillus, Byssochlamys, Gymnoascus e Paecilomyces, sendo o mais citado na literatura científica o Penicillium expansum (MACHINSKI JR \& MÍDIO, 1995). Esta micotoxina tem sido relatada por muitos autores como promotora de efeitos mutagênicos (KORTE \& RUCKET, 1980; KIRSCH, 1990), carcinogênicos (OSSWALD et al., 1978; BECCI et al., 1981) e teratogênicos (CIEGLER et al., 1976; SMITH et al., 1993).

A patulina tem sido encontrada contaminando diversas frutas, como o damasco, a cereja, a uva, a pêra, o pêssego, a ameixa e, principalmente, a maçã (FRANK et al., 1977; MACHINSKI JR \& MÍDIO, 1996; TANGNI et al., 2003). Quanto aos estudos sobre a contaminação de uvas ou suco de uvas por patulina, eles são poucos, como os citados por FRANK et al. (1976), MEYER (1978), ALTMAYER et al. (1982), CZERWIECKI (1984), KUBRAK et al. (1995) e SYLOS \& RODRIGUEZAMAYA (1999). Os principais fatores responsáveis pelo crescimento do Penicillium expansum e a produção da micotoxina em frutas são a atividade de água superior a 0,82 (NORTHOLT et al., 1978), a temperatura de 20 a $25^{\circ} \mathrm{C}$ (BULLERMAN, 1985) e as diversas fontes de carbono: frutose, glicose, sacarose e ácido málico (GAUCHER, 1979).

Em 1995, o Joint Expert Committee on Food Additives (JECFA), da Organização Mundial da Saúde (WHO) e da Organização de Alimentos e Agricultura (FAO), alterou a Ingestão Semanal Tolerável Provisória (PTWI) de $7 \mu \mathrm{g} \mathrm{kg}^{-1}$ de peso corpóreo/semana de patulina para uma Ingestão Diária Tolerável Máxima Provisória (PMTDI) de $0,4 \mu \mathrm{g} \mathrm{kg}^{-1}$ de peso corpóreo/ dia (WHO, 1995). Vários países estabeleceram o limite máximo permitido de $50 \mu \mathrm{g} \cdot \mathrm{kg}^{-1}$ para patulina em produtos para o consumo humano (FAO, 1997). Entretanto, a África do Sul e a Rússia têm recomendado o limite de $20 \mu \mathrm{g} \mathrm{kg}^{-1}$ de patulina em alimentos para bebês e $30 \mu \mathrm{g} \cdot \mathrm{kg}^{-1}$ para alimentos infantis, respectivamente (SA GOVT. GAZETTE, 1990; FAO, 1997). No Brasil, apenas as aflatoxinas possuem limites máximos toleráveis; as demais micotoxinas não apresentam limites de tolerância na legislação (BRASIL, 1996 e 2002).

Este trabalho teve por objetivo investigar a ocorrência de patulina em cachos de uva fina de mesa, da cultivar "Rubi" (Vitis vinifera L.), produzidos em Marialva-PR, com e sem sinais de podridão ácida.

\section{MATERIAL E MÉTODOS}

Foram realizadas coletas de 40 amostras em duas parreiras da cultivar "Rubi", do grupo Itália (V. vinifera L. cv. "Rubi"), em uma área com a doença, podridão ácida, do município de Marialva, localizado no noroeste do Estado do Paraná, Brasil, no período de dezembro de 2003 a janeiro de 2004. O tamanho mínimo de cada amostra foi de $500 \mathrm{~g}$.

O delineamento experimental utilizado foi inteiramente casualisado com quatro tratamentos e cinco repetições, ou seja, em duas áreas com a podridão ácida, foram coletados quatro tipos de amostras, com 5 repetições diferentes coletadas no mesmo dia e local, em cada uma das áreas, conforme as seguintes características: (I) sem sintomas de podridão ácida; (II) com sintomas, sem a remoção das bagas infectadas; (III) com sintomas, com a remoção das bagas infectadas, e (IV) com sintomas da doença, com a remoção das bagas infectadas e sanitização com hipoclorito $0,5 \%$ por 20 minutos. As amostras foram acondicionadas em sacos plásticos e transportadas em caixa refrigerada até o laboratório.

No laboratório, os cachos de uva foram lavados com água corrente, sendo que, em um dos tratamentos (IV), aquele com amostras que apresentavam sintomas da doença e que foram submetidas à retirada das bagas infectadas, foi realizada a imersão em solução de hipoclorito a $5 \%$ por 20 minutos e posterior lavagem em água corrente para avaliar o efeito de medidas de sanitização na redução da 
contaminação de patulina. Em seguida, as bagas das amostras de cada tratamento foram trituradas e filtradas em tamis de 20 mesh. Os sucos obtidos foram acondicionados em sacos plásticos e congelados à temperatura de $-20^{\circ} \mathrm{C}$.

O padrão de patulina foi obtido da Sigma Chemical Co (EUA). O preparo das soluções padrão de Patulina a $10 \mu \mathrm{g} \cdot \mathrm{mL}^{-1}$ foi realizado segundo o descrito no Manual de Métodos Oficiais de Análises da AOAC (1998).

A determinação de patulina foi realizada segundo o método descrito por TANNER \& ZANIER (1976), com modificações. Cinqüenta mililitros do suco foram transferidos para um funil de separação e adicionados de $100 \mathrm{~mL}$ de acetato de etila (Synth, Brasil), sob agitação durante dois minutos. O suco foi particionado mais duas vezes com $50 \mathrm{~mL}$ de acetato de etila. As camadas orgânicas foram combinadas e transferidas para um funil de separação. $\mathrm{O}$ extrato orgânico foi particionado com $50 \mathrm{~mL}$ de carbonato de sódio 1,5 \% (Merck, Alemanha). Evaporou-se a fase orgânica em banho de água a $40^{\circ} \mathrm{C}$. O resíduo obtido foi dissolvido em $100 \mu \mathrm{L}$ de etanol (Merck, Alemanha). Foram aplicados $10 \mu \mathrm{L}$ do extrato na cromatoplaca (Alugram ${ }^{\circledR}$ Sil G -sílicagel 60G, Macherey-Nagel, Alemanha), a $2 \mathrm{~cm}$ da base. Foram aplicados 1, 2, 3, 4, 5, $6,7,8,9$ e $10 \mu \mathrm{L}$ da solução padrão de uso de patulina $\left(10 \mu \mathrm{g} \cdot \mathrm{mL}^{-1}\right)$. A placa foi colocada em uma cuba nãosaturada contendo tolueno e acetato de etila (3:7). A patulina foi visualizada por incidência da luz ultravioleta longa após derivação com cloridrato de 3-metil-2benzotiazolinonaidrazona (MBTH) da Sigma Co. (EUA) a $0,5 \%$ em ácido fórmico 5\% (Synth, Brasil). Os limites de detecção e de quantificação do método foram de: 1,5 e $12 \mu \mathrm{g} \mathrm{kg}^{-1}$, respectivamente.

$\mathrm{O}$ controle da qualidade analítica foi realizado a cada conjunto de sete amostras, uma foi fortificada artificialmente, isto é, para as amostras extraídas no mesmo dia, uma quantidade de patulina foi adicionada em uma amostra previamente analisada e na qual não foi detectada a patulina, variando de 23,0 a $68,8 \mu \mathrm{g} \mathrm{kg}^{-1}$. Essas amostras foram usadas para avaliar a recuperação do método. Como critério de qualidade analítica, foi definida que a recuperação deveria estar entre 60 a 110\%, conforme HORWITZ et al.,1993.

Os dados climatológicos foram obtidos na Estação Climatológica da Universidade Estadual de Maringá.

\section{RESULTADOS E DISCUSSÃO}

A recuperação média do método foi de $72,3 \%$ para a patulina, conforme demonstra a tabela 1 .

A patulina não foi detectada em nenhuma das 40 amostras avaliadas. Os resultados sugerem que a patulina não é um contaminante comum em uvas, na presença ou ausência da podridão ácida, plantadas no Noroeste do Estado do Paraná. No Brasil, há relatos de patulina apenas em suco de maçã, como os citados por MACHINSKI JR \& MÍDIO (1996), os quais demonstraram que 15 amostras foram positivas com teores variando de 6 a $78 \mu \mathrm{g} \cdot \mathrm{L}^{-1}$, e por SYLOS \& RODRIGUEZ-AMAYA(1999), os quais analisaram um total de 111 amostras de sucos de frutas, sendo 30 de suco de maçã e 83 de frutas diversas tais como uva, abacaxi, mamão, goiaba, banana e manga, e encontraram apenas uma amostra positiva, de suco de maçã, com teor de patulina de $17 \mu \mathrm{g} \cdot \mathrm{L}^{-1}$.

Entretanto, deve-se salientar que a contaminação com esta micotoxina pode variar por diversos fatores. O gênero Penicillium, apesar da sua capacidade de se desenvolver em frutas no campo, é mais freqüente como fungo de armazenamento. Assim, fatores como as condições climáticas, a espécie de Penicillium, as cepas predominantes durante a podridão ácida e os tipos de uva podem mudar os resultados relatados por este presente estudo.

Os dados climatológicos no período da coleta de amostras (Tabela 2) mostraram-se favoráveis para a produção da patulina pelo Penicillium spp., uma vez que estes fungos são mesófilos, com faixa ótima para o crescimento e a produção da micotoxina entre $25^{\circ} \mathrm{Ce} 30^{\circ} \mathrm{C}$ (SOMMER et al., 1974; BULLERMAN,

Tabela 1 - Recuperação de amostras de uva fortificada com patulina.

\begin{tabular}{lccc}
\hline & \multicolumn{3}{c}{ Patulina } \\
\cline { 2 - 4 } Amostras & Quantidade adicionada $\left(\mu \mathrm{gkg}^{-1}\right)$ & Quantidade encontrada $\left(\mu \mathrm{gkg}^{-1}\right)$ & Recuperação $(\%)$ \\
\hline 1 & 23,0 & 16,1 & 70,0 \\
2 & 33,9 & 27,6 & 81,4 \\
3 & 33,9 & 28,7 & 84,7 \\
4 & 33,9 & 26,3 & 77,6 \\
5 & 67,8 & 40,7 & 60,0 \\
6 & 67,8 & 40,9 & 60,3 \\
& Recuperação & (Média \pm Desvio Padrão $)=$ & $72,3 \pm 10,6$ \\
\hline
\end{tabular}

Ciência Rural, v.38, n.1, jan-fev, 2008. 
Tabela 2 - Dados climatológicos do período da coleta de uvas com e sem podridão ácida na região de Marialva, PR.

\begin{tabular}{|c|c|c|c|c|c|}
\hline Data & $\begin{array}{c}\text { Variação das } \\
\text { temperaturas máximas } \\
\left({ }^{\circ} \mathrm{C}\right)\end{array}$ & $\begin{array}{l}\text { Variação das } \\
\text { temperaturas médias } \\
\left({ }^{\circ} \mathrm{C}\right)\end{array}$ & $\begin{array}{c}\text { Variação das } \\
\text { temperaturas mínimas } \\
\left({ }^{\circ} \mathrm{C}\right)\end{array}$ & $\begin{array}{l}\text { Média da umidade } \\
\text { relativa }(\%)\end{array}$ & $\begin{array}{c}\text { Índice pluviométrico } \\
\text { acumulado }\left(\mathrm{mm}^{3}\right)\end{array}$ \\
\hline$* 15 / 12 / 2003$ & $24,0-33,4$ & $20,2-28,5$ & $15,8-23,1$ & 76 & 46,7 \\
\hline$* * 08 / 01 / 2004$ & $28,0-31,4$ & $23,4-26,6$ & $16,5-21,6$ & 73 & 6,4 \\
\hline
\end{tabular}

* Período de 09/12/2003 a 15/12/2003.

** Período de $02 / 01 / 2004$ a 08/01/2004.

1985; DAMOGLOU et al., 1985; TANIWAKI et al., 1989) e atividade de água superior a 0,95 (DAMOGLOU et al., 1985).

A ausência de patulina neste estudo pode ser decorrente da presença de gêneros não produtores da micotoxina na podridão ácida (Cladosporium, Alternaria, Diploidia e Rhizopus), bem como, da ausência da espécie produtora da patulina (Penicillium). TANIWAKI et al. (1989), em estudo realizado em três variedades de maçãs e em suco industrializado da mesma fruta, observaram sinais visíveis de deterioração e crescimento de quatro espécies diferentes de Penicillium, porém apenas uma foi produtora de patulina.

Na podridão ácida, há uma contaminação com bactérias acéticas, portanto, produtoras de acetato de etila e ácido acético, como Gluconobacter spp. e Acetobacter spp. (MARCHETTI et al., 1984; BISIACH et al., 1986; DONÈCHE, 1992; GRAVOT et al., 2001). Este fato favorece a instabilidade da patulina na uva com a patologia, pois segundo RALLS \& LANE (1977), a patulina em meio contendo ácido acético é convertida em outros compostos rapidamente. Esta é outra hipótese que favorece o não aparecimento da patulina nas amostras avaliadas neste estudo.

\section{CONCLUSÃO}

Não foi detectada a ocorrência de patulina em uvas Itália (Vitis vinifera L. cv. Rubi) acometidas com a podridão ácida.

\section{REFERÊNCIAS}

ALTMAYER, B. et al. Analysis of patulin in grape juices and wine. Zeitschrift fur Lebensmittel-Untersuchung und Forschung, Berlin, v.175, n.3, p.175-178, 1982.

AOAC INTERNATIONAL. Official methods of analysis of AOAC International. 16.ed. 4.rev. Arlington, 1998 (Software Adobe and E-DOC/CJS).

BECCI, P.J. et al. Long-term carcinogenicity and toxicity studies of Patulin in the rat. Journal of Applied Toxicology, Chichester, v.1, p.256-261,1981.
BISIACH, M. et al. Possible integrated control of grapevine sour rot. Vitis, Siebendingen, v.25, p.118-128, 1986.

BRASIL, Agência Nacional de Vigilância Sanitária - ANVISA. RDC n. 274, 15 de outubro de 2002. Diário Oficial da União, Brasília, 16 de outubro de 2002.

BRASIL, Ministério da Agricultura, Abastecimento e Reforma Agrária. Portaria n. 183, 21 de março de 1996. Diário Oficial da União, Brasília, 25 de março de 1996.

BULLERMAN, L.B. Interactive effects of temperature and $\mathrm{pH}$ on mycotoxin producing molds. Journal of Food Science, Chicago, v.18, n.3, p.197-200, 1985

CIEGLER, A. et al. Teratogenicity of patulin and patulin adducts formed with cysteine. Applied and Environmental Microbiology, Washington, v.31, p.664-667, 1976.

CZERWIECKI, L. Detection and determination of patulin in Polish fruit wines. Rocznik Panstwowego Zakladny Higijenu, Warszawa, v.35, n.4, p.347-349, 1984.

DAMOGLOU, A.P. et al. Some factors governing the production of patulin in apples. Food Microbiology, London, v. 2, p. $3-10,1985$

DONÈCHE, B.J. Botrytized wines. In: FLEET, G.H. (Eds.). Wine microbiology and biotechnology. London: Harwood Academic, 1992. p.327-351.

FAO. Food and Agriculture Organization of the United Nations. Worldwide regulations for mycotoxins 1995. Rome: FAO, 1997. p.7-28. (Food and Agriculture Organization Food and Nutrition paper 64).

FRANK, H.K. et al. Patulin in lebensmittein pflanzlicher herkunft. 1 Kernobst und daraus hergestellte produkte. Zeitschrift fur Lebensmittel-Untersuchung und Forschung, Berlin, v.162, p.149-157, 1976.

FRANK, H.K. et al. Patulin in lebensmitteln pflanzlicher herkunft. 2. Verschiedene obstarten, gemüse und daraus hergestellte produkte. Zeitschrift fur LebensmittelUntersuchung und Forschung, Berlin, v.163, p.111-114, 1977.

GAUCHER, G.M. Mycotoxins - their biosynthesis in fungi: patulin and related carcinogenic lactones. Journal of Food Protection, Des Moines, v.42, n.10, p.810-814, 1979.

GIOVANNINI, E. Produção de uvas para vinho, suco e mesa. Porto Alegre: Renascença, 1999. p.302-303. 
GENTA, W. et al. Doenças fúngicas da parte aérea da videira nas safras de verão-outono e inverno-primavera nas regiões norte e noroeste do Paraná. Fitopatologia Brasileira, Brasília, v.26, p.424, 2001.

GRAVOT, E. et al. La pourriture acide. Phytoma, Paris, v.543, p.36-39, 2001.

GUERZONI, E.; MARCHETTI, R. Analysis of yeast flora associated with grape sour rot and of the chemical disease markers. Applied and Environmental Microbiology, Washington, v.53, p.571-573, 1987.

HORWITZ, W. et al. Reliability of mycotoxin assays - an update. Journal of the Association of Official Analytical Chemists International, Arlington, v.76, p.461-491, 1993.

IBGE. Instituto Brasileiro de Geografia e Estatística. Levantamento sistemático da produção agrícola. Capturado em 17 out. 2006. Online. Disponível na Internet http://www.sidra.ibge.gov.br.

KIRSCH, P.F. Production of a genomic DNA library in lambda phage for Penicillium patulum, and isolation and partial characterization of Patulin pathway induction-phase-specific clones from the library. Dissertation Abstracts International, Ann Arbor, v.50, n.8, p.3452b, 1990.

KORTE, A.; RUCKET, G. Chromosomal analysis in bonemarrow cells of Chinese hamsters after treatament with mycotoxins. Mutation Research, Amsterdam, v.78, p.4150, 1980 .

KUBRAK, E.M. et al. Contamination of food products by mycotoxins in Kyrgyzstan. Eurotox' 95, Toxicology Letters, Amsterdam, v.1/78, n.51, p.1-81, 1995.

LOUREIRO, V.; MALFEITO-FERREIRA, M. Spolaige yeasts in the wine industry. International Journal of Food Microbiology, Amsterdam, v.86, p.23-50, 2003.

MACHINSKI JR., M.; MÍDIO, A.F. Patulina em alimentos aspectos toxicológicos e analíticos. Revista de Farmácia e Bioquímica da Universidade de São Paulo, São Paulo, v.31, n.1, p.1-19, 1995.

MACHINSKI JR., M.; MÍDIO, A.F. Incidencia de Patulina en jugo de manzana industrializado. Alimentaria, Madrid, v.276, p.61-64, 1996.

MARCHETTI, R. et al. Recherche sur 1'etiologie d'une nouvelle maladie de la grappe: la pourriture acide. Vitis, Siebendingen, v.23, p.55-65, 1984.

MEYER, R.A. Occurrence of mycotoxin patulin in fruit and fruit products. Lebensmittel Industrie, Munchem, v.25, n.5, p. 224-225, 1978.
NORTHOLD, M.D. et al. Patulin production by some fungal species in relation to water activity and temperature. Journal of Food Protection, Des Moines, v.41, n.11, p.885-890, 1978.

OSSWALD, H. et al. Long-term testing of Patulin administered orally to Sprague-Dawley rats and Swiss mice. Food and Cosmetics Toxicology, London, v.16, p.243-248, 1978.

PROTAS, J.F.S. et al. A vitinicultura brasileira: realidade e perspectiva. Capturado em 29 dez. 2004. Online. Disponível na Internet: http://www.cnpuv.embrapa.br/publica/artigos/ vitinicultura.html.

RALLS, J.W.; LANE, R.M. Examination of cider vinegar for patulin using mass spectrometry. Journal of Food Science, Chicago, v.42, n.4, p.1117-1119, 1977.

SA GOVT. GAZETTE. South African Goverment Gazette. Regulations governing tolerances for fungus-produced toxins in foodstuffs. Pretoria: South African Goverment Gazette, 1990. p.R313.

SMITH, E.E. et al. Effects of patulin on postimplantation rat embryos. Archives of Environmental Contamination and Toxicology, New York, v.25, p.267-270, 1993.

SOMMER, N.F. et al. Production of patulin by Penicillium expansum. Applied Microbiology, Washington, v.28, p.589$593,1974$.

SÔNEGO, O.R.; GARRIDO, L.R . Doenças fúngicas da videira e seu controle. Capturado em 29 dez. 2004. Online. Disponível na Internet http://www.cnpuv.embrapa.br/publica/ viticultura/doevid.html.

SYLOS, C.M.; RODRIGUEZ-AMAYA, D. Incidence of patulin in fruits and fruit juices marketed in Campinas, Brazil. Food Additives and Contaminants, London, v.16, n.2, p.71-74, 1999.

TANGNI, E.K. et al. Patulin in domestic and imported applebased drinks in Belgium: occurrence and exposure assessment. Food Additives and Contaminants, London, v.20, n.5, p.482-489, 2003.

TANIWAKI, M.H. et al. Bolores produtores de patulina em maçã e suco industrializado. Coletâneas do ITAL, Campinas, v.19, n.1, p.42-49, 1989.

TANNER, H.; ZANIER, C. Ueber eine neue patulin inbestimmung fruchtsaften und konzentraten. Schweizerische Zeitschrift fur Obst- und Weinbau, Wadenswil, v.112, p.656-662, 1976.

WHO. World Health Organization. Evaluation of certain food additives and contaminants. In: Report of the Joint Food and Agriculture Organization/World Health Organization Expert Committee on Food Additives, 44. Geneva: WHO, 1995. p.36-38, (Technical Report Series 859). 